\title{
Educación en valores, ética y moral
}

María de Lourdes Pacheco González

\section{Acerca de la educación en valores}

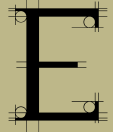

n épocas recientes se ha dado gran auge al tema de los valores, esto ha llevado a hablar de educar en valores o clarificación de valores. Sin embargo, el trasfondo de esta educación en valores es la educación moral, que según Josep Puig Rovira:

se convierte en el nervio central de la educación porque quiere dar dirección y sentido al ser humano en su conjunto. La educación moral, entendida como uno de los aspectos particulares de la educación o entendida como eje transversal de todo el proceso educativo, es un aspecto clave de la formación humana.

La educación moral es algo que se lleva a cabo desde el hogar, ya que en toda sociedad se busca conformar en sus miembros un cierto tipo de conducta que permita no solamente la convivencia entre éstos sino que tal convivencia sea lo más sana posible y que permita que todos construyan "el modo como se quiere ser y el modo como se quiere vivir" y entonces alcancen la felicidad. Esta práctica lleva implícitos los valores, es la educación informal, que no tiene nombre ni apellido.

\section{Cursos formales}

Para darle sentido a esa educación se han implementado cursos formales de educación moral, de la cual se dice que:

- Deberá transmitir aquellos recursos morales que puedan ser de utilidad en la resolución de los conflictos de valor, y asimismo deberá ayudar a desarrollar las capacidades morales que han de permitir a cada sujeto enfrentarse crítica y creativamente a dichos conflictos de valor.

- [...] Educar moralmente [es] educar en valores, más que en modelos de hombre [...] [en] la educación moral [...] lo que importa es avistar valores y aprender a saborearlos, sabiendo que por atractivos que resulten unos personajes u otros, yo voy a tener que crear 
el mío, el que nadie puede representar por mí; pero que merece la pena hacerlo con valores que valgan.

A partir de las citas anteriores se puede decir que la educación moral tiene una gran tarea en la vida de los seres humanos, y a través de los cursos formales que se imparten en las instituciones educativas desde educación primaria hasta las de nivel superior lo que se quiere es ayudar a los estudiantes a conformar su personalidad moral, a que se sensibilicen tanto de sí mismos como de los otros para que a partir de ello sean capaces de ponerse en el lugar del otro; pero no sólo eso sino que también asuman responsabilidad frente a las diversas manifestaciones de valores y los conflictos surgidos a partir de tal diversidad y por tanto se enfrenten a ellas de una mejor manera.

Se pueden encontrar fundamentalmente dos tipos de cursos formales:

\section{a) Cursos de ética y moral}

En general, los cursos de moral tienden a ser una presentación histórica de autores y corrientes, o también -más frecuentemente-son fuente de adoctrinamiento; se busca que el alumno pasivamente reciba toda la información por parte del profesor y asuma como absolutos los valores presentados, sin permitir el más mínimo grado de crítica o enjuiciamiento acerca de lo dado; estos cursos, dice Adela Cortina, "[pretenden] darle ya las respuestas y evitar que siga pensando: encerrarle en su propio universo moral, para que no se abra a otros horizontes".

En este tipo de cursos, la educación moral -entendida como se describe anteriormente-pierde todo sentido, ya que no hay toma de conciencia por parte de los educandos para acercarse a la crítica y comprensión de la moral y los valores, ni manera para hacer que a partir de ello forme parte de su ser y de su vida.

Los cursos de ética, por su parte, suelen centrarse en la presentación de conceptos y su significado, describen los actos morales y qué elementos forman parte de ellos, entre otros aspectos. Aquí existe apertura para que el alumno piense por sí mismo, y entonces la educación moral como ayuda para formar la personalidad moral del estudiante, se puede decir, está presente. Generalmente estos cursos forman parte de los estudios de los niveles medio superior y superior.

b) Cursos de clarificación de valores

La clarificación de valores:

[...] estimula el inicio de un proceso de autodescubrimiento mediante el [cual] el niño identifica sus propios valores [...]. El propósito de la clarificación de valores es brindar a los estudiantes la oportunidad de implicarse en temas que ellos elijan, para que descubran o clarifiquen sus propias creencias y valores.

Algo que es importante tomar en cuenta con respecto a la clarificación de valores es:

[...] que está basada en un concepto concreto de cada valor. [y] Para calificar algo como un valor, tiene que pasar por los seis pasos siguientes: a) ser elegido, b) elegido libremente, c) elegido entre otras alternativas, d) ser deseado por la persona que lo elige, e) darlo a conocer ante los demás y f) no haberlo hecho sólo ocasionalmente, sino regularmente.

Como se puede leer, la clarificación de valores está estrechamente ligada a la educación moral aquí presentada, y se puede encontrar desde la formación elemental hasta la educación superior a través de una serie de actividades de diversa índole que llevan al sujeto (sea éste niño, adolescente o adulto) a identificar qué valores son los que posee o vive de manera un tanto inconsciente, y entonces los vuelva conscientes y les dé la importancia debida.

Esta forma de educar en la moral considera que "[...] cada individuo debe, mediante un proceso enteramente personal, discernir y clarificar los valores que quiere hacer suyos, superando los límites, condicionamientos y presiones impuestos". ${ }^{8}$ Tiende a hacer que los

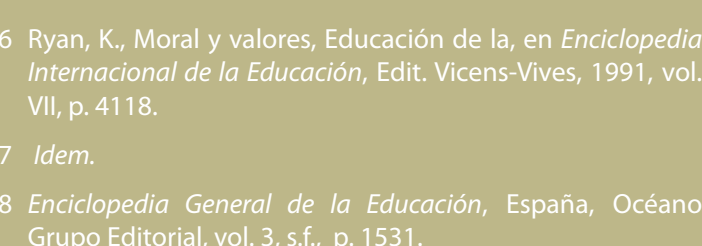


estudiantes dejen atrás la pasividad y que asuman una actitud creadora y de actividad frente a los valores, para que así haya un verdadero y auténtico compromiso con los valores, lo que en esta época hace mucha falta.

\section{La educación en valores, ética y moral en la Universidad Autónoma de Aguascalientes}

La ética, ya sea como materia curricular o como ideal, es inherente a la Universidad Autónoma de Aguascalientes. En el Modelo Educativo Institucional se habla de un sujeto con una dimensión "ético-moral (normas de comportamiento para el bien y el mal, sus fundamentos, sus valores, los ideales de vida, la conciencia moral, la voluntad para tomar decisiones libres)", , así como de una formación valoral donde:

los estudiantes desarrollarán una perspectiva ética y moral caracterizada por comportamientos sensibles y razonamientos consistentes respecto a los valores que la Institución señala en su Ideario. ${ }^{10}$

Así es como la Universidad Autónoma de Aguascalientes, preocupada por formar no sólo profesionistas sino personas con valores, conocimientos y actitudes para ponerlos al servicio de ellos mismos y de la sociedad, ha incluido en los planes de estudio materias con corte humanista, especialmente ético; así, el Departamento de Filosofía, particularmente la Academia de Ética, pone a disposición de sus estudiantes los diversos programas y cursos de Ética Profesional, Ética en las Organizaciones, Formación en Valores Profesionales, entre otros. Estos cursos buscan llevar a los futuros profesionistas a tomar conciencia de la importancia que la ética, la moral, los valores y la libertad tienen en los diversos ámbitos de su vida.

\section{Fuentes de consulta}

Cortina, A., El quehacer ético. Guía para la educación moral, España, Aula XXI-Santillana, 1996.

Puig Rovira, Josep, La construcción de la personalidad moral, España, Ediciones Paidós Ibérica, 1996.

Ryan, K., "Moral y valores, Educación de la", en Torsten Husen y T. Neville Postlethwaite (Coords.), Enciclopedia Internacional de la Educación, vol. VII, 1991.

S/A, Enciclopedia General de la Educación, España, Océano. Grupo Editorial, vol. 3, s.f.

Universidad Autónoma de Aguascalientes, Modelo Educativo Institucional. Correo universitario, sexta época, número 16, publicado el 15 de marzo de 2007. Recuperado de http://www.uaa.mx/ el 21 de enero de 2013.

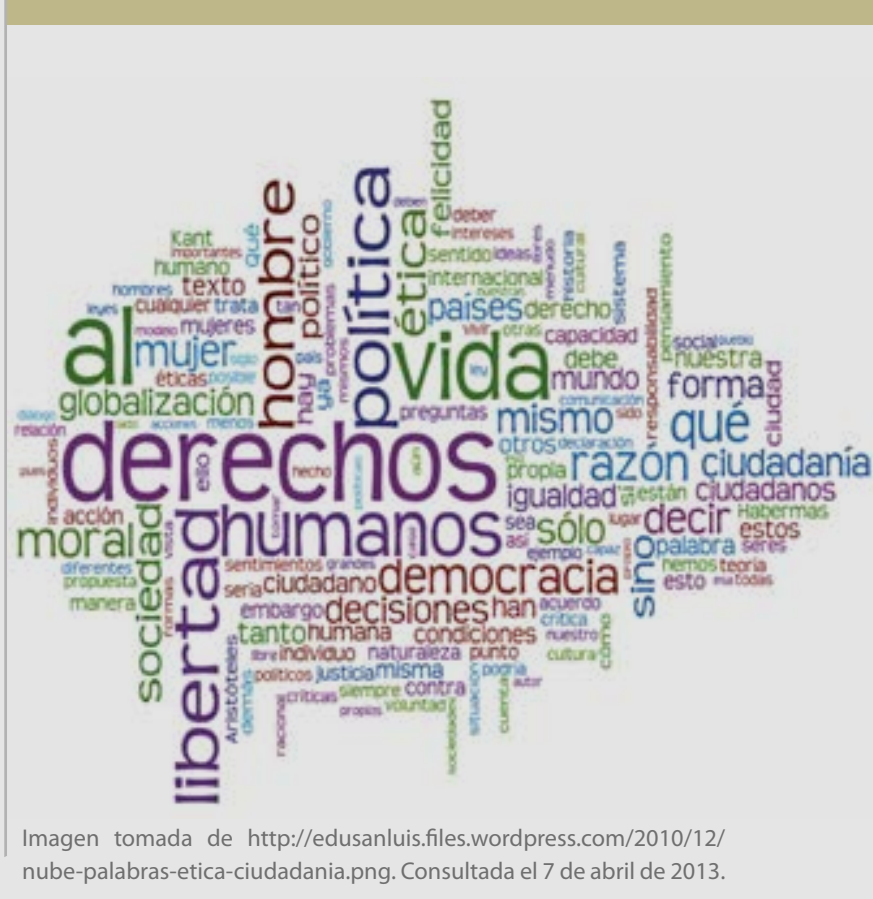

9 Modelo Educativo Institucional de la Universidad Autónoma de Aguascalientes, Correo Universitario, Sexta época, Número 16, 15 de marzo de 2007, p. 5. Recuperado de http://www.uaa.mx/ nu/ el 21 de enero de 2013.

10 lbid., p. 8. 